\title{
The Game Analysis on Skilled Teachers Competition of Higher Vocational Colleges
}

\author{
Huixia Hao \\ Economic and Trade Department \\ Zhengzhou Electric Power College \\ ZhengZhouCity, China \\ 13703908932@163.com
}

\author{
Ye Ren \\ Economic and Trade Department \\ Zhengzhou Electric Power College \\ ZhengZhouCity, China \\ Yezi11023@163.com
}

\begin{abstract}
With the development of higher vocational education, it is becoming fierce that the competition of skilled teachers in higher vocational colleges. All of candidates are more and more focus on skilled teachers. The comprehensive strength of higher vocational colleges is not only beneficial to personnel training and skills upgrading, but also to testing the teachers' practical results. In other words, on the decrease of candidates circumstances, the final competition of higher vocational colleges is bocoming skilled teachers' competition. Based on the two stage dynamic game mode, This paper makes an analysis of how to establish reasonable incentive policy in higher vocational colleges. The first stage is that the college leaders determine each skilled teachers' remuneration, the second stage is a quantitative analysis method that the skilled teachers decide what kind of effort degree they make after knowing wages. All the words, through this method, not only teachers can make better errorts create value, but also the higher vocational colleges are able to paly a part in the reasonable proposal on the employment polocy.
\end{abstract}

Keywords-game; higher vocational education; skilled teachers; competition

\section{INTRODUCTION}

Nowadays, it is a very hot problem that the higher vocational education in China. It indicates that the beginning of the higher occupation education since the first time to establish the 13 vocational colleges in 1980. The higher vocational education had been developing rapidly since our country decided to speed it up in 1999. By the end of 2010, there are 1246 higher vocational colleges at home(1). Unfortunately, the training of skilled teachers could not keep up with development of occupation education. In recent years, with the constant enlargement of the scope of higher vocational education, the skilled teachers shortage becomes an important obstacle of each college enrollment plan. One side, it is very clear for higher skilled teachers that work positioning, who should focus on training students' practical ability continuously in our contury. After graduating, students can quickly adapt to the job, at the same time, business are satisfied with work for candidites. The other side, with the quickly development of higher vocational education, teachers can not adapt to the teaching mode of combination working with learning. Many teachers are lack of practical ability training, so it is difficult to connection between enterprise position requirement and teaching plan. Therefore, only through constantly training and enhancing practice ability, teachers may adapt requirements of higher vocational education. However, it will be a long time that the teachers' training, which isn't able to adapt to the development of higher vocational education. So, in order to enhance vocational colleges competitiveness, the skilled teachers' competition is becoming fiercely competitive.

\section{RESEARCHER METHOD}

The Game theory mainly research on equilibrium decision problems when the decision-making subject behavior interacts(2). That is to say, when the decisionmaking subject choices are influenced by selection effects of some people or enterprises, in turn who also affect the decision subject. Here the subject can be a person or a business, or even a body and a group, for example, the skilled teachers and higher vocational colleges in this paper. According to the concept of player in the game theory,it means that the person or organization is responsible for independent strategy in the game process. For convenience, suppose that there are two players in the game, the skilled teachers and higher vocational colleges. In this paper, we conside the game skilled teachers and between higher vocational colleges according to the complete information dynamic game(3) (4).

\section{A METHOD OF SKILLED TEACHERS COMPETITION}

\section{A. The Model of Novel Method}

In this paper,the mathematical expression derived can be supposed:

- The skilled teachers don't have a part-time job.

- All the teachers have the same base pay, life subsidy $H$ and pay for a classhour $H_{k}$, they are called the salary of each teacher every month, the expresson is $H_{c}=k \cdot H_{k}+H, k$ means periods.

- Just only one that make outstanding contribu-tions in teaching work shall be rewarded by colleges every month.

- For the skilled college teachers' achievement, $y_{i}=e_{i}+\alpha_{i}, i=1,2, \cdots n$, we use the $e_{i}$ to exprass an effort of teachers' abilities of teaching and practice; and we use $\alpha_{i}$ to indicate a random perturbation 
because of emotional factors, the mean value is 0 , the probability for the $f(\alpha)$.

- We use the negative utility function $g(e)$ to show each skilled teachers' efforts, it is an upward concave curve, $g^{\prime}(e)>0, g^{\prime \prime}(e)>0$, it means that the negative effect with the effort increase, which consistent with reality.

- The result of wages is certain, we use the $H_{\beta}$ to express the outstanding performance teachers. On the contrary, the general can only get monthly salary $H_{c}$, which means that the outstanding can get an extra income monthly $H_{\beta}-H_{c}$.

This dynamic game model is made of two simultaneous selection phase, the first stage is that higher vocational colleges determine the different salary for skilled teachers: $H_{\beta}$ and $H_{c}$. The second stage is that the teachers take action after they knowing the salary system, in other words, they should decide to select their effort.We suppose the costs to include wages only for higher vocational colleges,so the payoff function is:

$$
y=\sum_{i=1}^{n} y_{i}-H_{\beta}-(n-1) H_{c}
$$

All skilled teachers wages are made up of salary and bonus each month, we can use the negative utility function $u$ express:

$$
u=H_{\alpha}-g(e)\left(g(e) \geq 0, H_{\alpha}=H_{\beta} \text { 或 } H_{c}\right)
$$

The study methods are adopted adverse deduce induction. If the salary system has been set, both $H_{\beta}$ and $H_{c}$ are not function $e_{i}$ but constant factors. The game goes into a static game for teachers by making effort increase their income, so the result is that the skilled teachers can choose to constitute a Nash equilibrium $\left(e_{1}^{*}, e_{2}^{*}, \cdots e_{n}^{*}\right)$.

Next,we set up all of skilled teachers are risk-neutral, and it must be an expected maximization problem in order to try their best. For each teacher $i, e^{*}$ must be the solution of value problem.

$$
\begin{aligned}
& \max _{e>0}\left\{H_{\beta} \cdot p\left[y_{i}\left(e_{i}\right)>y_{j}\left(e_{j}\right)\right]+H_{c} \cdot p\left[y_{i}\left(e_{i}\right) \leq y_{i}\left(e_{i}\right)\right]-g\left(e_{i}\right)\right\} \\
= & \max _{e>0}\left\{\left(H_{\beta}-H_{c}\right) p\left[y_{i}\left(e_{i}\right)>y_{j}\left(e_{j}\right)\right]+H_{c}-g\left(e_{i}\right)\right\}
\end{aligned}
$$

In this fomulas,we use $p$ to stand for the probability of making remarkable achievement teachers, so $y_{i}\left(e_{i}\right)=e_{i}+\alpha_{i}, i=1,2, \cdots n$.

$$
y_{j}\left(e_{j}^{*}\right)=\max \left(y_{k}\left(e_{k}^{*}\right)\right)_{k=1,2, \cdots i-1, i+1, \cdots, n}
$$

According to the first order derivative of fomulas (3) ,we can get skilled teachers to select efforts to must satisfy the basic conditions:

$$
\frac{\left(H_{\beta}-H_{c}\right) \partial p\left[y_{i}\left(e_{i}\right)>y_{j}\left(e_{j}^{*}\right)\right]+H_{c}-g\left(e_{i}\right)}{\partial e_{i}}=0
$$

So:

$$
\left(H_{\beta}-H_{c}\right) \frac{\partial p\left[y_{i}\left(e_{i}\right)>y_{j}\left(e_{j}^{*}\right)\right]}{\partial e_{i}}=g^{\prime}\left(e_{i}\right)
$$

The fomulas (4) shows that the marginal income of skilled teachers' effort should be equal the marginal disutility of effort.

$$
\begin{aligned}
& p\left[y_{i}\left(e_{i}\right)>y_{j}\left(e_{j}^{*}\right)\right]=p\left[e_{i}+\alpha_{i}>e_{j}^{*}+\alpha_{j}\right] \\
= & p\left[\alpha_{i}>e_{j}^{*}+\alpha_{j}-e_{i}\right] \\
= & 1-F\left(e_{j}^{*}+\alpha_{j}-e_{i}\right)
\end{aligned}
$$

Finally, inserting formula (5) into formula (4), we can be available to:

$$
\left(H_{\beta}-H_{c}\right) f\left(e_{j}^{*}+\alpha_{j}-e_{i}\right)=g^{\prime}\left(e_{i}\right)
$$

While in a symmetric Nash equilibrium:

$$
e_{1}^{*}=e_{2}^{*}=\cdots=e_{n}^{*}=e^{*}
$$
effect:

Therefore, all skilled teachers have the same incentive

$$
\left(H_{\beta}-H_{c}\right) f\left(\alpha_{j}\right)=g^{\prime}\left(e^{*}\right)
$$

The fomula (6) indicates the static Nash equilibrium of skilled teachers, in other words,it is the optimal level fomula for skilled teachers under the conditions of determined salary system. Bacause the function $g(e)$ is increasing, the more 
the function $\left(H_{\beta}-H_{c}\right)$, the bigger Teachers' salary gap and the higher effort $e^{*}$ each teacher. So, it will be make the difference in teaching practice.

\section{B. The Measures of Realizing The Novel Method}

In order to make incentive mechanism effect, the fundamental condition is that skilled teachers are willing to take part in work and competition. If each teachers are unsatisfied with competition, the incentive mechanism would be invalid. Therefore, it is the basic condition for all skilled teachers that the income no less than change another job, otherwise they do not want to participate in work.

In the symmetric Nash equilibrium, we suppose that every teacher change another job to get the highest income $I_{g}$, while each teachers will select the same strategies and get equal opportunity on extra bonus $\frac{1}{n}$ :

$$
p\left[y_{i}\left(e_{i}\right)>y_{j}\left(e_{j}^{*}\right)\right]=\frac{1}{n}
$$

If we don't consider the penalty compensation problem, higher vocational colleges establish the salary policy to be:

$$
\frac{1}{n} H_{\beta}+\frac{n-1}{n} H_{c}-g\left(e^{*}\right) \geq I_{g}
$$

Higher vocational colleges want to cut down expenses, so they must select the minimum cost strategy:

$$
\begin{aligned}
& \frac{1}{n} H_{\beta}+\frac{n-1}{n} H_{c}-g\left(e^{*}\right)=I_{g} \\
& H_{\beta}=n I_{g}+n g\left(e^{*}\right)-(n-1) H_{c}
\end{aligned}
$$

The fomula (7) indicates that skilled teachers are satisfied with the competitive bottom line. Under these given conditions, the expression of pay-off function for higher vocational colleges:

$$
\begin{gathered}
y=\sum_{i=1}^{n} y_{i}-H_{\beta}-(n-1) H_{c} \\
\sum_{i=1}^{n}\left(\alpha_{i}+e^{*}\right)-H_{\beta}-(n-1) H_{c} \\
=n e^{*}+\sum_{i=1}^{n} \alpha_{i}-H_{\beta}-(n-1) H_{c}
\end{gathered}
$$

Because $\alpha_{i}$ indicates the random variable with a mean of 0 of the probability, we think that:

$$
\sum_{i=1}^{n} \alpha_{i}=0
$$

So:

$$
y=n e^{*}-H_{\beta}-(n-1) H_{c}
$$

Higher vocational colleges aim to make the pay-off function maximize, accordingly:

$$
\max _{H_{\beta}>H_{c}>0}\left[n e^{*}-H_{\beta}-(n-1) H_{c}\right]
$$

Inserting formula (7) into formula (8), we can be available to:

$$
\begin{aligned}
& \max _{e \geq 0}\left[n e^{*}-n I_{g}-n g\left(e^{*}\right)+(n-1) H_{c}-(n-1) H_{c}\right] \\
= & \max _{e \geq 0}\left[n e^{*}-n I_{g}-n g\left(e^{*}\right)\right]
\end{aligned}
$$

We should solve the first order derivative of fomulas (9):

$$
\begin{gathered}
{\left[n e^{*}-n I_{g}-n g\left(e^{*}\right)\right]^{\prime}=0} \\
1-g^{\prime}\left(e^{*}\right)=0
\end{gathered}
$$

Inserting formula (6) into formula (10), we can be available to:

$$
\left(H_{\beta}-H_{c}\right) f\left(\alpha_{j}\right)=1
$$

In the specific incentive strategy, as long as we know the specific form of negative utility function $g(e)$, we can get the teachers' maximum salary $e^{*}$ through the fomula (10). If we insert the expression $e^{*}$ into equilibrium equation (6) and (7), We can get the best wage $H_{\beta}^{*}$ and $H_{c}^{*}$.

If in the forth hypothesis, the mean of random variable $\alpha_{i}$ can indicate the function $E\left(\alpha_{i}\right) \neq 0$ :

$$
y=n e^{*}+\sum_{i=1}^{n} \alpha_{i}-H_{\beta}-(n-1) H_{c}
$$


If we know the condition to express $\sum_{i=1}^{n} \alpha_{i}>0$, higher vocational colleges will pay more than in the condition $\sum_{i=1}^{n} \alpha_{i}=0$. Because we use $\alpha_{i}$ to indicate a random perturbation of emotional factors, higher vocational colleges should try to enhance the skilled teachers' personal positive emotional factors. In words, higher vocational colleges should may try their best to solve the practical problems in order to keep the teachers' personal negative emotion to a minimum.

\section{CONCLUSIONS}

Based on all of the above analysis, we draw the conclusions of skilled teachers competition:

First, higher vocational colleges should put forward reasonable incentive policy. If the income gap can not reach the initial goal, skilled teachers will consider that they are unworthy of hard work.

Secondly, salary should keep up with job tasks and performance. According to teachers' performance, colleges should pay the expected salary. In other words, as long as teachers have successfully done their work, they should get enough salary.

Thirdly, colleges should construct a reasonable selection mechanism to improve principal conditions. The selection mechanism of colleges is the essential action that colleges improve overall quality of teachers and promote the whole level and efficiency of colleges through innovation of the post appointment system.

Forthly, only breaking the salary limit, colleges improve the work ability of teachers, so that they can try their best to work. Therefore, colleges can improve the teaching and working condition and strengthen their professional training in order to improve the teachers' work ability and efficiency.

List and number all bibliographical references in 9-point Times, single-spaced, at the end of your paper. When referenced in the text, enclose the citation number in square brackets, for example [1]. Where appropriate, include the name(s) of editors of referenced books. The template will number citations consecutively within brackets [1]. The sentence punctuation follows the bracket [2]. Refer simply to the reference number, as in [3] — do not use "Ref. [3]" or "reference [3]" except at the beginning of a sentence: "Reference [3] was the first..."

Number footnotes separately in superscripts. Place the actual footnote at the bottom of the column in which it was cited. Do not put footnotes in the reference list. Use letters for table footnotes.

Unless there are six authors or more give all authors' names; do not use "et al.". Papers that have not been published, even if they have been submitted for publication, should be cited as "unpublished" [4]. Papers that have been accepted for publication should be cited as "in press" [5]. Capitalize only the first word in a paper title, except for proper nouns and element symbols.

For papers published in translation journals, please give the English citation first, followed by the original foreignlanguage citation [6].

\section{REFERENCES}

[1] The Ministry of education in 2010: Statistics Bulletin of Educational Development. China Higher Vocational Education Network

[2] Weiying Zhang. Game Theory and Information Economics. Shanghai People's Publishing House, 1996:26-31

[3] Guangjiu Li. The Game Theory Basic Course. Chemical Industry Press, 2005:11-15

[4] Shiyu Xie. Economic Game Theory. Fudan University press, 2006:19-39

[5] Chenghua Zhang. The Game Analysis for Management of College Teachers. Taiyuan Normal University Journal. 2009, 2 (4): 30 - 33

[6] Yalan He. College Graduates Employment Market Game Analysis. Journal of Beijing Institute of Technology (SOCIAL SCIENCE EDITION), 2005, 6 (2): 15 - 18

[7] Xiangnong Qian. University Teachers' Salary Management Research. Master Dissertation of East China Normal University, 2005

[8] Pinliang Luo. China's Research Universities Salary System. The Research and Development management, 2004, 2 (5): 18 - 20

[9] Yansui Yang. Construction for College Teachers Occupation characteristics of labor pay system. Chinese HigherEducationResearch, 2004. 